\title{
Body mass and body weight: a dual reference system in biology
}

\author{
Masa y peso corporales: un sistema dual de referencia en biología
}

\author{
BRUNO GÜNTHER ${ }^{1} \&$ ENRIQUE MORGADO $2,3^{*}$ \\ ${ }^{1}$ Emeritus Professor of Physiology and Physiopathology, Universidad de Concepción y Universidad de \\ Valparaíso, Chile \\ ${ }^{2}$ Programa de Fisiopatología, Instituto de Ciencias Biomédicas, Facultad de Medicina, Universidad de \\ Chile, Salvador 486, Casilla 16038, Santiago, Chile \\ ${ }^{3}$ Programa de Fisiopatología, Facultad de Ciencias Médicas, Universidad de Santiago de Chile, Santiago, \\ Chile; e-mail (corresponding author)*: emorgado@machi.med.uchile.cl
}

\begin{abstract}
The aim of the present study was to compare two different biological similarity criteria, one was based on body mass (M) as a theoretical reference system in accordance with the MLT-system of physics, while the other utilized the body weight $(\mathrm{W})$ for the same purpose. The mass-dependent allometry should be applied during space flights as well as during fetal and newborn conditions of life, whereas the weight-dependence should prevail in earth-bound physiology. The above mentioned distinctions are relevant not only for the specific metabolic rates but also for numerous biological time functions, as for instance for the heart and respiratory rates of all mammals, whose allometric exponent is $b=-0.09$ during fetal life, and $\mathrm{b}=-0.25$ in all adult specimens.
\end{abstract}

Key words: dimensional analysis, biological similarity, allometry, biological time, fetal life, space physiology.

\section{RESUMEN}

El objetivo del presente trabajo fue la comparación de dos diferentes criterios de similitud, uno basado en la masa corporal (M) como sistema teórico de referencia de acuerdo con el sistema MLT de la Física, en tanto que el otro utilizó el peso corporal (W) con este mismo propósito. La alometría dependiente de la masa debería aplicarse durante los vuelos espaciales así como durante la vida fetal y la condición de recién nacido, en tanto que la dependencia del peso debe prevalecer en la fisiología terrestre. La distinción antes mencionada es relevante, no sólo para el metabolismo específico y también para numerosas funciones biológicas en relación con funciones de tiempo, como ser con las frecuencias cardiaca y respiratoria de todos los mamíferos cuyo exponente alométrico es $b=-0,09$ durante la vida fetal, y $b=-0,25$ en todos los especimenes adultos.

Palabras clave: análisis dimensional, similitud biológica, alometría, tiempo biológico, vida fetal, fisiología en el espacio.

\section{INTRODUCTION}

In the biological literature it is customary to make no distinction between body mass (M) and body weight $(\mathrm{W})$, since in both cases the utilized unit is the kilogram $(\mathrm{kg})$. This fact has been recently emphasized by Prothero (2002), who expressed the following: "when biologists measure the size of an animal, they usually measure its weight or length, not its mass. (The fact that mass and weight are numerically the same at the earth's surface is irrelevant to my point). It may be that the indiscriminate use of mass as a measure of body size serves to give to scaling studies the (unwarranted) aura of doing physics".
However, since Newton's times, in his second law of motion, he established that $\mathrm{W}=\mathrm{Ma}$, where $\mathrm{W}$ is a force and, a, an acceleration $[\mathrm{a}]=\left[\mathrm{LT}^{-2}\right]$, which on earth corresponds to the acceleration of gravity $\left(\mathrm{g}=9.8 \mathrm{~m} \mathrm{~s}^{-2}\right)$. From a dimensional point of view, by applying the MLT-system of physics, where $\mathrm{M}=$ mass, $\mathrm{L}=$ length, and $\mathrm{T}=$ time, mass or the quantity of matter has the dimension $\left[\mathrm{M}^{1} \mathrm{~L}^{0} \mathrm{~T}^{0}\right]$, in contrast with the dimension of weight which is $\left[\mathrm{M}^{1} \mathrm{~L}^{1} \mathrm{~T}^{-2}\right]$. It is noteworthy, that before the advent of the space flight era, the above mentioned dimensional distinction may have been neglected as a purely academic issue, but since then, the paramount scientific and technical effort to place in orbit a living being around the earth, acquired great relevance for the human species. 


\section{A MECHANICAL SIMILARITY}

Galileo (1638) compared for the first time forms and functions of animals and plants on the basis of Euclidean geometric principles, while Newton (1687) introduced a quantitative analysis of structures of different size, being one the prototype (p) and the other the model $(\mathrm{m})$.

Subsequently, Newton formulated the rules of mechanical_similarity on the basis of two postulates, (1) the constancy of density of prototype and model, and (2) the duration of one period of a physical pendulum, which varied with the square root of its length. The symbols of the dimensional analysis, which in their present form are due to Maxwell, with $\mathrm{M}=$ mass, $\mathrm{L}=$ length, and $\mathrm{T}=$ time can be applied to any physical variable (Y), yielding:

$$
\mathrm{Y}=\mathrm{M}^{\alpha} \mathrm{L}^{\beta} \mathrm{T}^{\gamma}
$$

where $\alpha, \beta$, and $\gamma$ are the exponents of the corresponding dimensions (M, L, T). By applying two postulates: (1) the constancy of density $\left(\mathrm{ML}^{-3}\right)=$ 1 , and (2) the relationship of $\mathrm{L}$ and $\mathrm{T}$ in a physical pendulum $\left(\mathrm{T} \sim \mathrm{L}^{1 / 2}\right.$, where $\sim$ stands for proportional), it has been possible to express (LeviCivita \& Amaldi 1951) the three-dimensional equation 1 , as one of only one-dimension:

$$
Y=M^{p \alpha+q \beta+r \gamma}
$$

where $\mathrm{p}, \mathrm{q}$ and $\mathrm{r}$ corresponds to the appropriate exponents of the dimensions $\mathrm{M}, \mathrm{L}$ and $\mathrm{T}$.

In the case of mechanical similarity, this transformation yields:

$$
\mathrm{Y}=\mathbf{M}^{\alpha+1 / 3 B+1 / 6 \gamma}
$$

as shown in Table 1.

The coefficient $1 / 3$ for the exponent $b$ comes from the Euclidean metrics, since $\mathrm{ML}^{-3}=1$, hence $\mathrm{L}=\mathrm{M}^{1 / 3}$, while the coefficient $1 / 6$ for the exponent of time is derived from the physical pendulum, where $\mathrm{T}=\mathrm{L}^{1 / 2}=\left(\mathrm{M}^{1 / 3}\right)^{1 / 2}=\mathrm{M}^{1 / 6}$.

\section{THEORY OF BIOLOGICAL SIMILARITIES}

Huxley (1932) introduced into biology the allometric equation,

$$
\mathrm{Y}=\mathrm{aW}
$$

where $\mathrm{Y}$ is a biological variable, $\mathrm{W}$ is body weight and, $b$, the allometric exponent, which characterizes each function. However, numerous biological parameters could not be described accurately by equation 3 , the difference between predicted

TABLE 1

Evolution of the different theories of similarity and the corresponding coefficients, $\mathrm{p}, \mathrm{q}$ and $\mathrm{r}$,

\begin{tabular}{|c|c|c|c|c|c|}
\hline Item & $\begin{array}{l}\text { Similarity theory } \\
\text { Exponents of MLT }\end{array}$ & $\begin{array}{c}\text { Mass (M) } \\
\alpha\end{array}$ & $\begin{array}{c}\text { Length (L) } \\
\beta\end{array}$ & $\begin{array}{c}\text { Time }(\mathrm{T}) \\
\gamma\end{array}$ & Reference \\
\hline & $\begin{array}{l}\text { Coefficients for } \\
\quad \alpha, \beta, \gamma\end{array}$ & $\mathrm{p}$ & q & $\mathrm{r}$ & $\begin{array}{c}\mathrm{b}=\mathrm{p} \alpha+\mathrm{q} \beta+\mathrm{r} \gamma \\
\text { Yates }(1979)\end{array}$ \\
\hline 1 & $\begin{array}{l}\text { Mechanical } \\
\text { (physics) }\end{array}$ & 1 & $1 / 3$ & $1 / 6$ & $\begin{array}{c}\text { Galileo (1638) } \\
\text { and Newton (1687) }\end{array}$ \\
\hline 2 & $\begin{array}{l}\text { Biological } \\
\text { (ancient) }\end{array}$ & 1 & $1 / 3$ & $1 / 3$ & $\begin{array}{c}\text { Lambert \& Teissier } \\
\text { (1927) }\end{array}$ \\
\hline 3 & Elastic & 1 & $1 / 4$ & $1 / 4$ & McMahon (1973) \\
\hline $\begin{array}{c}4 \\
5 \mathrm{~A}\end{array}$ & $\begin{array}{l}\text { Statistical analysis of } 203 \\
\text { empirical allometric equations } \\
\text { New biological similarity, and }\end{array}$ & 0.96 & 0.35 & 0.30 & Günther et al. (1992) \\
\hline & as function of body weight & $5 / 6$ & $1 / 3$ & $1 / 4$ & $\begin{array}{l}\text { Present study: } \\
\text { (A) on Earth } \\
\text { Equation } 8\end{array}$ \\
\hline $5 \mathrm{~B}$ & $\begin{array}{l}\text { New biological similarity, } \\
\text { as function of body mass }\end{array}$ & 1 & $1 / 3$ & $1 / 4$ & $\begin{array}{c}\text { On space and for the fetus } \\
\text { in uterus } \\
\text { Equation } 6\end{array}$ \\
\hline
\end{tabular}
for the exponents of mass, length, and time

Evolución de las diferentes teorías de similitud y los coeficientes p, q, y r correspondientes, para los exponentes de masa, largo y tiempo 
and observed allometric exponents being large, especially for those parameters which included a time dimensions. Lambert \& Teissier (1927) introduced the concept of "biological similarity", where the first Newton's postulate was maintained, whereas the second was replaced by an a priori postulate $\mathrm{L}=\mathrm{T}=\mathrm{M}^{1 / 3}$, which yields finally,

$$
\mathbf{Y}=\mathbf{M}^{\alpha+1 / 3 \beta+1 / 3 \gamma}
$$

This equation had a much better predictive value than the one strictly based on mechanical similarity. Nevertheless, consistent discrepancies between observed and predicted values were still apparent for numerous parameters of allometric equations, such a biological times $(b=1 / 4)$, metabolic rate $(b=3 / 4)$, cardiac output $(b=3 / 4)$, total peripheral resistance $(b=-3 / 4)$, pulmonary ventilation $(b=3 / 4)$. These differences motivated a further statistical revision of 203 empirical allometric exponents with respect to the coefficient of the exponent of the time dimension (Günther et al. 1992). In accordance with three kinds of evidences (Günther \& Morgado 1982, Calder 1984, Sernetz et al. 1985, West et al. 1997), the coefficient of the time exponent $(\gamma)$ was changed from $1 / 3$ to $1 / 4$, resulting the equation,

$$
\mathbf{Y}=\mathbf{M}^{\alpha+1 / 3 \beta+1 / 4 \gamma}
$$

Although dimensional analysis from its early conception dealt with body mass, empirical allometric equations are expressed always as function of body weight. However, the physical difference between $\mathrm{M}$ and $\mathrm{W}$ was already established by Newton's second law, Force $=\mathrm{Ma}$, being, a, an acceleration, from which $\mathrm{W}=\mathrm{Mg}$. The better predictive values of biological, versus mechanical similarity indicates that the effects of $\mathrm{g}$ on many biological variables is not independent of M. Second, and important in the context of the present discussion, it indicates that in equation 4 the use of $\mathrm{M}$ rather than $\mathrm{W}$ will lead to different allometric exponents, $b$.

As mentioned above, the physical dimension of the acceleration of gravity $[\mathrm{g}]=\left[\mathrm{LT}^{-2}\right]$, and when the dimension of length (L) and time (T) are expressed as functions of body mass (M), then:

$$
\mathrm{M}^{1 / 3} \mathrm{M}^{-2(1 / 4)}=\mathrm{M}^{1 / 3-1 / 2}=\mathrm{M}^{-1 / 6}
$$

It should be noted, that the effect of gravity ( $\mathrm{g}$ ) is limited to the mass-dimension, since both length (L) and time (T) are not affected in the present case, because $\mathrm{Lg}$ nor $\mathrm{Tg}$ have a precise physical meaning. Thus, the conversion of weight $\mathrm{W}=\mathrm{Mg}$ into its mass - equivalencies yields:

$$
\mathrm{M}^{1 / 1-1 / 6}=\mathrm{M}^{5 / 6}
$$

Therefore, when we are dealing with body weight (W) of an organism living on earth, the equivalent mass expression will be:

$$
b=5 / 6 \alpha+1 / 3 \beta+1 / 4 \gamma
$$

Finally, Günther \& Morgado (2002) have recently discussed this matter.

\section{THE ELASTIC SIMILARITY}

McMahon (1973, 1983) combined engineering principles concerning elasticity, buckling and bending of supporting bones, with the principle of similitude, after recognizing that animals are not geometrically similar. He came to the conclusion, that the critical length of bones varied with body mass as follows $\mathrm{L} \sim \mathrm{M}^{1 / 4}$, while the corresponding diameter, $\mathrm{d}$, changed as $\mathrm{d} \sim \mathrm{M}^{3 / 8}$, and the cross-sectional areas, A, varied as $\mathrm{A} \sim\left(\mathrm{M}^{3 / 8}\right)^{2}=$ $\mathrm{M}^{3 / 4}$. Furthermore, he assumed that maximal muscular power, as well as basal metabolic rate, varied also as the three-fourth power of body mass. With regards to biological time functions, he concluded that the relationship (see Table 1) should be:

$$
\mathrm{T} \sim \mathrm{L} \sim \mathrm{M}^{1 / 4}
$$

In sum, McMahon's studies dealt exclusively with a very homogeneous group of mammals, the ungulates. However, his theory of elastic similarity was not supported for materials extending over the entire range of mammals (SchmidtNielsen 1984).

\section{STATISTICAL ANALYSIS OF EMPIRICAL ALLOMETRIC EQUATIONS}

For the numerical analysis of different theories of similarity, Yates (1979) has recommended the following algebraic equation:

$$
b=p \alpha+q \beta+r \gamma
$$

where the coefficients $\mathrm{p}, \mathrm{q}$, and $\mathrm{r}$ are unknown, while the exponents $\alpha, \beta$, and are determined by the dimensional analysis, in accordance with the MLT-system of physics.

From the multiple linear regression analysis of two hundred and three empirical allometric equations, (Günther et al. 1992), which were found in 
the literature (Peters 1983, Calder 1984), the following equation could be obtained:

$$
b_{R}=0.96 \alpha+0.35 \beta+0.30 \gamma
$$

The corresponding determination coefficient in equation 12 was $\mathrm{r}^{2}=0.993$. It is interesting to note that the empirical coefficients are very close to the a priori values proposed by Lambert $\&$ Teissier (1927).

\section{THE EFFECTS OF BUOYANCY DURING FETAL LIFE}

The measured body weight of the fetus, W, is the product of its mass and the acceleration, or $\rho_{\mathrm{f}} \mathrm{Vg}$, where $\rho_{\mathrm{f}}$ is its body density, and following Withers (1992), nearly $1,075 \mathrm{~kg} \mathrm{~m}^{-3}$. In the liquidfilled uterine environment, the $\mathrm{W}$-force is opposed by the buoyancy-force, $\mathrm{B}$, which is generated by a body in its tendency to float or rise, when submerged into a fluid. The value of the buoyancy is determined by,

$$
\mathrm{B}=\rho \mathrm{Vg}
$$

where $\rho$ is the density of the liquid medium, and $\mathrm{V}$ the volume of the fetus. Since W and B oppose each other, the effective weight, $\mathrm{W}_{\text {eff }}$, of the fetus is,

$$
\mathrm{W}_{\text {eff }}=\left(\rho_{\mathrm{f}}-\rho_{\mathrm{a}}\right) \mathrm{Vg}
$$

where $\rho_{a}=1,008 \mathrm{~kg} \mathrm{~m}^{-3}$ is the density of the amniotic fluid (Döring 1960).

The ratio $\mathrm{W}_{\text {eff }} / \mathrm{W}$ equals

$$
\left(\rho_{\mathrm{f}}-\rho_{\mathrm{a}}\right) / \rho_{\mathrm{f}}=(1.075-1.008) / 1.075=0.062,
$$

or $6.2 \%$ of W. Therefore, when allometric scaling is applied to mammals, one would expect that for those physiological variables which are dimensionally dependent on $\mathrm{M}$, the exponent, $\mathrm{b}$, should differ between the fetal and postnatal condition. Specifically, the former could be better represented by equation (6), whereas the latter would be represented by equation (8). Reeves et al. (1972) reported data of arterial blood pressure from fetuses of various species, as compared to those of the adults, as illustrated in Fig. 1. The inter-species comparisons of newborns resulted in an allometric exponent of 0.169 , whereas the same analysis among adult mammals gave an exponent of 0.032 . In accordance with the theory of biological similarity (Günther 1975, Günther et al. 1992), the expected allometric exponent for

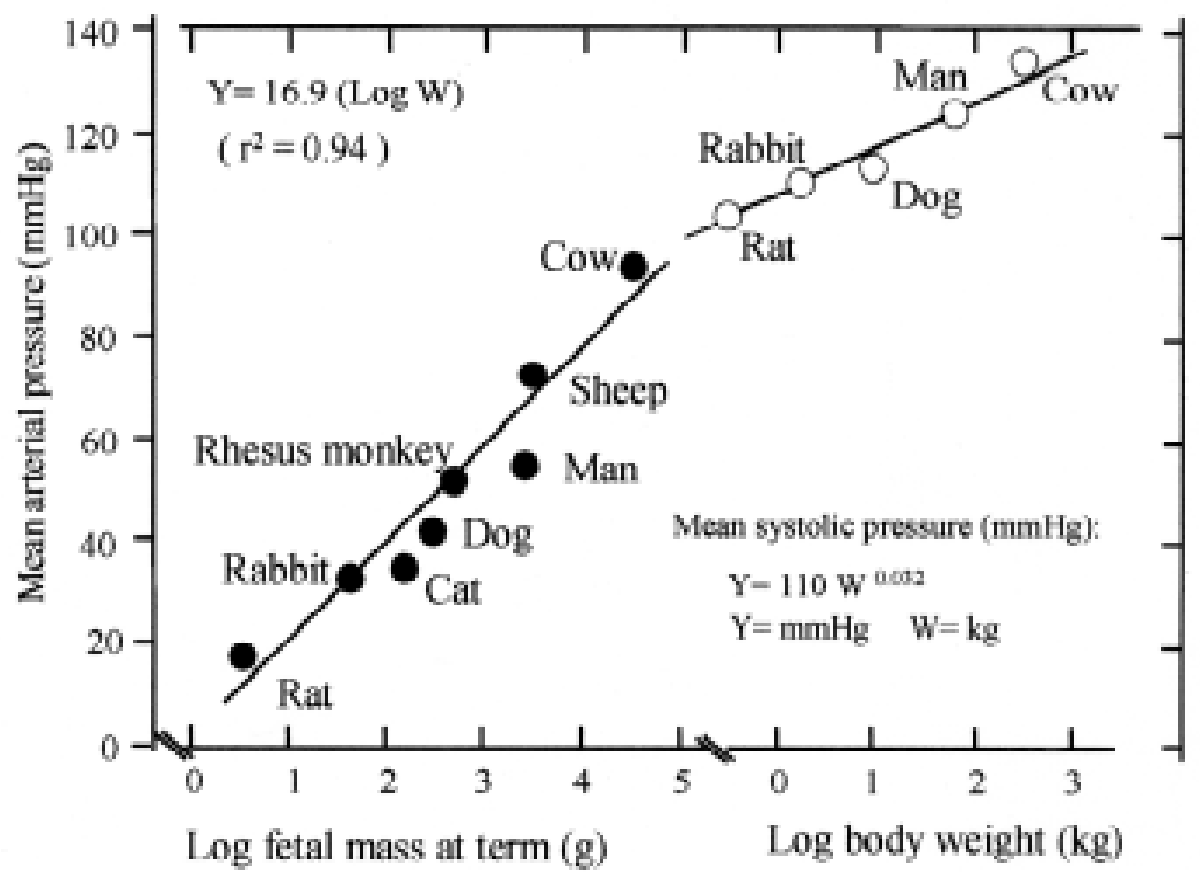

Fig. 1: Semi-logarithmic plot of the mean arterial pressure $(\mathrm{mmHg})$ of the mammalian fetus (body mass in $\mathrm{g}$ ), in comparison with adult mammals (body weight in $\mathrm{kg}$ ), which are represented by the corresponding allometric equation $\mathrm{P}=110 \cdot \mathrm{W}^{0.032}$.

Grafico log-log de la presión arterial media $(\mathrm{mmHg})$ del feto de mamífero (masa corporal en gramos), en comparación con los mamíferos adultos (peso corporal en $\mathrm{kg}$ ). La ecuación alométrica obtenida por regresión es $\mathrm{P}=110 \mathrm{~W}^{0.032}$. 
systemic arterial pressure should be 0.00 , when expressed as a function of $\mathrm{W}$ (equation 8 ), and 0.17 when expressed as function of $M$ (equation 6). Hence, the latter is one almost identical with the exponent obtained from the experimental observations in the fetuses at term.

Aortic blood pressure and other physiological variables are reviewed in Table 2. For the given parameters with $\mathrm{M}$ or $\mathrm{L}$ in their physical dimensions, the observed, $\mathrm{O}$, allometric exponents reported in the literature compare extremely well with those predicted, $\mathrm{P}$, and according to the criteria given above, that is M-dependency for the fetal-neonatal functions (equation 6), and W-dependency for the adults (equation 8). The only exception is the resistance of the respiratory system in the neonatal period (item 2 of Table 2), which, with an experimentally obtained exponent $\mathrm{b}=-0.75$, differs substantially from the predicted -0.58 one. Probably the rapid growth of the lung structures and the breathing of air in the early postnatal phases imposes an important deviation from the fetal pattern of fluid breathing, yielding an allometric relationship close to the aerobic breathing pattern of the adults.

It is interesting to consider the time dependent parameters, such as breathing rate and heart rate, because no a priori reasoning permits to anticipate which of the two correlations, with $\mathrm{M}$ or $\mathrm{W}$, could be stronger. In fact, given that the spacefilling fractal- like branching pattern of the circulatory and respiratory system are similar, both in the fetus and adult organisms, the same allometric exponent should be found, namely $b=-1 / 4$
(McMahon \& Bonner 1983, Calder 1984, West et al. 1997), whether the reference parameter is $\mathrm{M}$ or $\mathrm{W}$. On the other hand, since the oxygen cascade from the environment to the intracellular mitochondria includes the respiratory and circulatory convection pathways functionally coupled in series with cellular metabolism (Weibel 1984), it seems appropriate to consider the possibility that time-dependent biological variables may bear a relationship with specific metabolic rate (i.e., oxygen consumption $/ \mathrm{kg}$ ). In fact, mass-specific metabolic rate scales to $\mathrm{M}^{0.75} / \mathrm{M}^{1}=\mathrm{M}^{-0.25}$, which is the same allometric exponent consistently found among adult mammals for heart and breathing rates, as for almost all chronological phenomena in adult living beings (Peters 1983, Calder 1984). In the perinatal period, specific metabolic rate scales to $\mathrm{M}^{0.92} / \mathrm{M}^{1}=\mathrm{M}^{-0.08}$; hence, one would expect a similar exponent for both heart and respiratory rates. Indeed, this is the case, as represented in Table 3. Fig. 2 plots the changes in heart rate as function of body weight in humans, separately considering the data before and after birth. Whereas postnatally the relationship has a negative slope (-0.21), prenatally the slope is almost nil $(b=-0.04$, data from Altman \& Dittmer 1964). A similar exponent, $b=-0.06$, can be obtained either by plotting data of ultrasonic measurements at various times of gestation, or those of fetus species of different size (Ibarra-Polo et al. 1972, Meier et al. 1983). Breathing rate, measured in newborns of twenty three species, had an allometric exponent of -0.09 , much less than the adult value, $\mathrm{b}=-0.25$, and almost identical to that

\section{TABLE 2}

Dimensional analysis of seven biological functions and the predicted $(\mathrm{P})$ and observed $(\mathrm{O})$ allometric exponents (b) in adult mammals (A) and during fetal life (B)

Análisis dimensional de siete funciones biológicas y los exponentes alométricos (b) predichos $(\mathrm{P})$ y observados (O) en mamíferos adultos (A) y durante la vida fetal (B)

\begin{tabular}{|c|c|c|c|c|c|c|c|c|c|}
\hline \multirow[t]{3}{*}{ Item } & \multirow[t]{3}{*}{ Variable } & \multicolumn{3}{|c|}{ Physical dimension } & \multicolumn{2}{|c|}{ (A) In adult mammals } & \multicolumn{2}{|c|}{ (B) During fetal or neonatal life } & \multirow{3}{*}{$\begin{array}{l}\text { References for } \\
\text { column B, } \\
\text { observed (0) }\end{array}$} \\
\hline & & M & $\mathrm{L}$ & $\mathrm{T}$ & Predicted $(\mathrm{P})$ & Observed $(0)$ & Predicted $(\mathrm{P})$ & Observed (0) & \\
\hline & & $\alpha$ & B & $\gamma$ & (Equation 8) & & (Equation 8) & & \\
\hline 1 & Aortic blood pressure & -1 & -1 & -2 & 0 & 0.032 & 0.17 & 0.169 & Reeves et al. (1972) \\
\hline 2 & $\begin{array}{l}\text { Resistance of } \\
\text { respiratory system }\end{array}$ & 1 & -4 & -1 & -0.75 & -0.82 & -0.58 & -0.75 & Mortola (1987) \\
\hline \multirow[t]{2}{*}{3} & Heart rate & 0 & 0 & -1 & -0.25 & -0.25 & -0.09 & -0.06 & Meier et al. (1983) \\
\hline & Heart rate & 0 & 0 & -1 & -0.25 & -0.25 & -0.09 & $-0.06 \mathrm{Ib}$ & Ibarra-Polo et al. (1972) \\
\hline \multirow[t]{2}{*}{4} & Standard metabolic rate & 1 & 2 & -3 & 0.75 & 0.75 & 0.91 & 0.88 & Mortola (1987) \\
\hline & Standard metabolic rate & 1 & 2 & -3 & 0.75 & 0.75 & 0.91 & 0.92 & Mortola (2001) \\
\hline 5 & Respiratory ventilation & 0 & 3 & -1 & 0.75 & 0.75 & 0.91 & 0.91 & Mortola (2001) \\
\hline 6 & Respiratory frequency & 0 & 0 & -1 & -0.25 & -0.25 & -0.09 & -0.09 & Mortola (2001) \\
\hline 7 & Tidal volume & 0 & 3 & 0 & 1.00 & 1.00 & 1.00 & 1.01 & Mortola (2001) \\
\hline \multicolumn{2}{|c|}{ Determination coefficients } & & & & & $r^{2}=0.9986$ & & $\mathrm{r}^{2}=0.9920$ & \\
\hline
\end{tabular}


predicted from mass-specific metabolic rate (Table 3).

In conclusion, the differences in allometric scaling of physiological variables of mammals in the perinatal period compared to those of the adults can be explained in accordance with the theory of biological similarity, by taking into account the counteracting effect of buoyancy on weight.

\section{AN ALTERNATIVE MODEL OF ALLOMETRY: ORGAN- ISMS AS FRACTAL AND OPTIMIZED TRANSPORT NETWORKS}

An entirely different approach, concerning the origin of allometric scaling laws, was recently proposed by West et al. (1997). These authors developed a quantitative model for mammals, which comprises: (1) the existence of a network, which must reach all parts of a three-dimensional body by means of a self-similar fractal likebranching system; (2) that a minimum energy should be required for the transport of materials in a fluid medium; (3) that the terminal branches of the network should be size-invariant units (capillaries); (4) that the total hydrodynamic resistance of the system should also be minimized.

In sum, this novel approach has combined energetics with fractal design, as a kind of interplay between physical and geometric constrains, with the purpose of integrating morphological and functional characteristics of almost all living beings.

West's model has a good predictive power, since structural and functional variables were in close agreement with experimentally measured values, as exemplified in Table 3 .

The main difference between this novel approach and the present study is that these authors emphasized the fractal nature of the transport system within each organism, while in our case the specific metabolic rates yielded a fractal time dimension. In both cases, appeared the 1/4-power of body weight as the most relevant conclusion of the corresponding allometric scaling law.

\section{DISCUSSION}

The difference between mass and weight was clearly established already by Newton. However, in the biological sciences both terms are utilized indistinctly, because all living beings on earth are submitted to a constant gravitational field, which from a dimensional point of view yields [M] for mass and $\left[\mathrm{MLT}^{-2}\right]$ for weight.

The first attempt to apply systematically the dimensional analysis and the criteria of similitude to living beings was made by Lambert \& Teissier (1927). Unfortunately, these authors utilized the MLT-system of the physical science for

TABLE 3

Comparison between predicted and observed allometric reduced exponents (b) for eleven cardiovascular functions of mammals, and the corresponding values given by West et al. (1997)

Comparación entre los exponentes alométricos reducidos (b) predichos y observados para once funciones cardiovasculares de mamíferos, y los valores correspondientes publicados por West et al. (1997)

\begin{tabular}{|c|c|c|c|c|c|c|c|c|c|c|}
\hline \multirow[t]{3}{*}{ Item } & \multirow[t]{3}{*}{ Variable } & \multicolumn{3}{|c|}{ Physical dimension } & \multicolumn{3}{|c|}{ Present study } & \multicolumn{3}{|c|}{ West et al. (1997) } \\
\hline & & M & $\mathrm{L}$ & $\mathrm{T}$ & Predicted & Observed & Difference & Predicted & Observed & Difference \\
\hline & & $\alpha$ & B & $\gamma$ & (Equation 8) & & & & & \\
\hline 1 & Aorta radius & 0 & 1 & 0 & 0.33 & 0.36 & -0.027 & 0.375 & 0.360 & 0.015 \\
\hline 2 & Aorta pressure & 1 & -1 & -2 & 0.00 & 0.032 & -0.032 & 0.00 & 0.032 & -0.032 \\
\hline 3 & $\begin{array}{l}\text { Aorta blood } \\
\text { velocity }\end{array}$ & 0 & 1 & -1 & 0.08 & 0.07 & 0.01 & 0.00 & 0.07 & -0.07 \\
\hline 4 & Blood volume & 0 & 3 & 0 & 1.00 & 1.00 & 0.00 & 1.00 & 1.00 & 0.00 \\
\hline 5 & Circulation time & 0 & 0 & 1 & 0.25 & 0.25 & 0.00 & 0.25 & 0.25 & 0.00 \\
\hline 6 & Circulation distance & 0 & 1 & 0 & 0.33 & N.D.* & - & 0.25 & ND & - \\
\hline 7 & Cardiac stroke volume & 0 & 3 & 0 & 1.00 & 1.03 & -0.03 & 1.00 & 1.03 & -0.03 \\
\hline 8 & Cardiac frequency & 0 & 0 & -1 & -0.25 & -0.25 & 0.00 & -0.25 & -0.25 & 0.00 \\
\hline 9 & Cardiac output & 0 & 3 & -1 & 0.75 & 0.74 & 0.01 & 0.75 & 0.74 & 0.01 \\
\hline 10 & Total resistance & 1 & -4 & -1 & -0.75 & -0.76 & -0.01 & -0.75 & -0.76 & -0.01 \\
\hline 11 & Metabolic rate & 1 & 2 & -3 & 0.75 & 0.75 & 0.00 & 0.75 & 0.75 & 0.00 \\
\hline 12 & \multicolumn{4}{|c|}{ Determination coefficients } & \multicolumn{3}{|c|}{$\mathrm{r}^{2}=0.999$} & \multicolumn{3}{|c|}{$r^{2}=0.998$} \\
\hline
\end{tabular}

$* \mathrm{ND}=$ no data available 


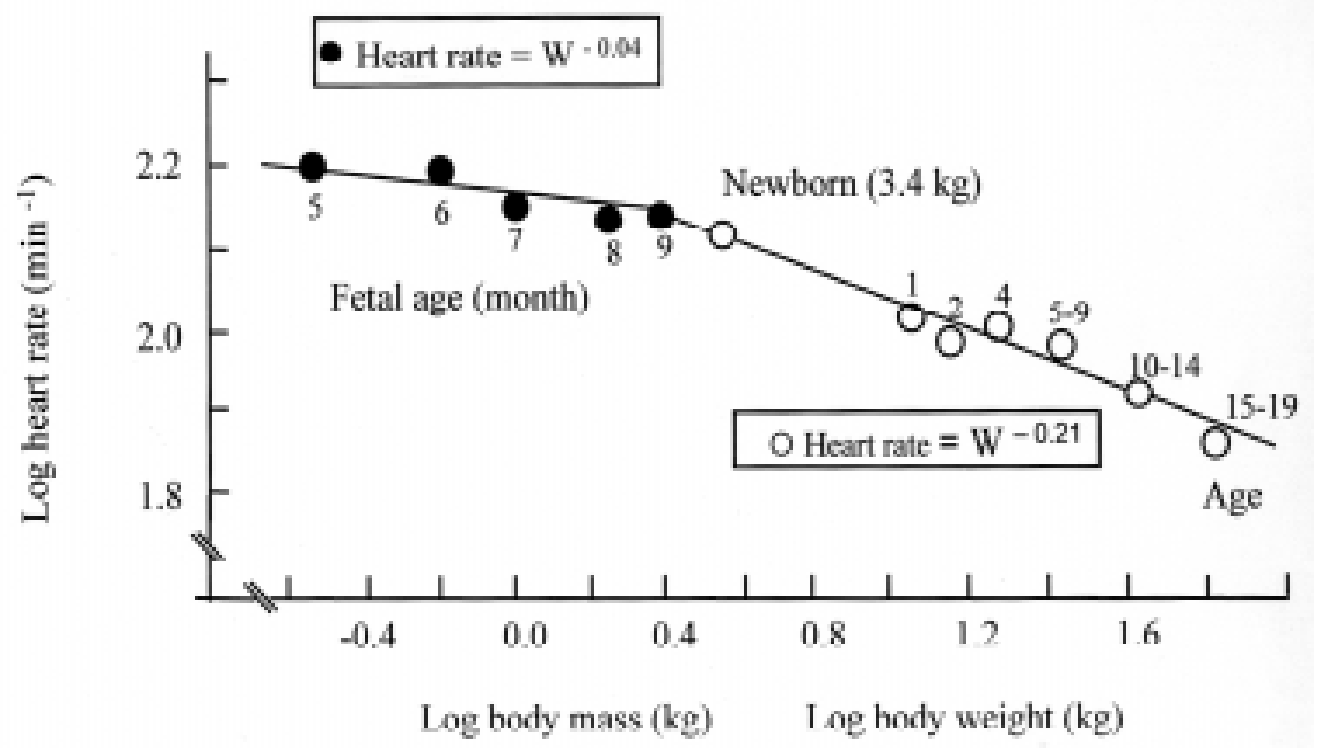

Fig. 2: Double logarithmic plot of heart rate (beats $\mathrm{min}^{-1}$ ) as function of body weight in the fetal (filled symbols) and postnatal life (open symbols). Data are from Altman \& Dittmer (1964).

Gráfico log-log de la frecuencia cardiaca (latidos $\mathrm{min}^{-1}$ ) en función de la masa corporal en el feto (círculos llenos) y en la vida post natal (círculos vacíos). Los datos provienen de Alman \& Dittmer (1964).

the dimensional analysis, and did not made the distinction between mass and weight. Finally, they applied Newton's concept of the reduced exponent, $b$, only as a function of the mass dimension, whose numerical value could be compared with the empirical findings expressed in accordance with Huxley's allometric equation, $\mathrm{Y}=$ $\mathrm{aW}^{\mathrm{b}}$.

From the comparative physiology of the respiratory functions first, during fetal and newborn life, and second, in adult mammals, it was found that the corresponding allometric exponents, $b$, were significantly different. The essential difference deals with the buoyancy effect during fetal life, in comparison with the body weight condition of adult specimens.

From this physical duality, two different allometric equations evolved, one as function of body mass and the other as function of body weight. The corresponding predicted allometric exponents were closely correlated with the empirically found exponents.

All physiological time scales are of empirical origin (Calder 1984), while the metabolic time scales (Weibel 1984) are based on the "specific oxygen consumption", or the metabolic rate per unit body mass $\left(\mathrm{M}^{0.75} / \mathrm{M}=\mathrm{M}^{-0.25}\right)$ or body weight $\left(\mathrm{V}_{\mathrm{O} 2} / \mathrm{W}\right)$. In consequence, the «metabolic time» is the reciprocal of metabolic rate (Schmidt-Nielsen 1984), being the allometric exponent $b=0.25$, the same as for the duration of the heartbeat.
In contrast, several authors (Butler et al. 1987, Prothero 2002) have postulated that the dimensional analysis and the theories of biological similarity are "unlikely to provide explanations applicable to scale-up in diverse species". However, since the original publication of Lambert \& Teissier (1927), these authors have carefully avoided the problem of the physical dimensions of the different biological variables by using thoroughly the ratio of mass, length and time between prototype (p) and model $(\mathrm{m})$, such as $\mathrm{Mp} / \mathrm{Mm}=\mu, \mathrm{Lp} / \mathrm{Lm}=$ $\lambda$, and $\mathrm{Tp} / \mathrm{Tm}=\tau$.

\section{ACKNOWLEDGEMENTS}

We are grateful to Dr. Carlos Holzmann (Professor of Electrical Engineering, University of Chile, Santiago, Chile) for helpful suggestions during the preparation of this manuscript.

\section{LITERATURE CITED}

ALTMAN PL \& DS DITTMER (1964) Biological data book. Federation of American Societies for Experimental Biology, Washington, District of Columbia. $633 \mathrm{pp}$.

BUTLER JP, HA FELDMAN \& JJ FREDBERG (1987) Dimensional analysis does not determine a mass exponent for metabolic scaling. American Journal of Physiology 253: R195-R199. 
CALDER WA (1984) Size, function and life history. Harvard University Press, Cambridge, Massachusetts. $431 \mathrm{pp}$.

DÖRING GK (1960) Physiologie der Fortpflanzung. In: Rosenmann HV (ed) Lehrbuch der Physiologie des Menschen, Volume 1: 428-472. Urban \& Schwarzenberg, München, Germany.

GÜNTHER B (1975) Dimensional analysis and theory of biological similarity. Physiological Reviews 55: 659699.

GÜNTHER B \& E MORGADO (1982) Theory of biological similarity revisited. Journal of Theoretical Biology 96: 543-559.

GÜNTHER B, U GONZÁLEZ \& E MORGADO (1992) Biological similarity theories: a comparison with the empirical allometric equations. Biological Research 25: 7-13.

GÜNTHER B \& E MORGADO (2002) An invariant number of the respiratory system of mammals: newborn and adult. Respiration Physiology and Neurobiology 130: 327-331.

HUXLEY JS (1932) Problems of relative growth. Methuen, London, United Kingdom. 273 pp.

IB ARRA-POLO AA, E GUILOFF \& C GÓMEZ-ROGERS (1972) Fetal heart rate throughout pregnancy. American Journal of Obstetrics and Gynecology 113: 814 818.

LAMBERT R \& G TEISSIER (1927) Théorie de la similitude biologique. Annales de Physiologie et Physicochemie Biologique (France) 3: 212-246.

LEVI-CIVITA T \& U AMALDI (1951) Compendio di meccanica razionale. Nicola Zanichelli SPA, Bologna, Italy. $482 \mathrm{pp}$.

MCMAHON TA (1973) Size and shape in biology. Science 179: 1201-1204.

MCMAHON TA \& JT BONNER (1983) On size and life. Scientific American Library, New York, New York. $255 \mathrm{pp}$.

Associate Editor: Francisco Bozinovic

Received September 30, 2002; accepted December 26, 2002
MEIER PR, DK MANCHESTER, FC BATTAGLIA \& G MESCHIA (1983) Fetal heart rate in relation to body mass. Proceedings of the Society for Experimental Biology and Medicine 172: 107-110.

MORTOLA JP (1987) Dynamics of breathing in newborn mammals. Physiological Reviews 67: 187-243.

MORTOLA JP (2001) Respiratory physiology of newborn mammals: a comparative perspective. John's Hopkins University Press, Baltimore, Maryland. 344 pp.

PETERS RH (1983) The ecological implications of body size. Cambridge University Press, Cambridge, United Kingdom. 329 pp.

PROTHERO J (2002) Perspectives on dimensional analysis in scaling studies. Perspectives in Biology and Medicine 45: 175-189.

REEVES JT, FS DAOUD \& M GENTRY (1972) Growth of the fetal calf and its arterial pressure, blood gases, and hematologic data. Journal of Applied Physiology 32: $240-244$.

SCHMIDT-NIELSEN K (1984) Scaling: why is animal size is so important? Cambridge University Press, Cambridge, United Kingdom. 241 pp.

SERNETZ M, B GELLÉRI \& J HOFFMANN (1985) The organism as bioreactor. Interpretation of the reduction law of metabolism in terms of heterogeneous catalysis and fractal structure. Journal of Theoretical Biology 117: 209-239.

WEIBEL ER (1984) The pathway for oxygen. Harvard University Press, Cambridge, Massachusetts. 425 pp.

WEST GB, JH BROWN \& BJ ENQUIST (1997) A general model for the origin of allometric scaling laws in biology. Science 276: 122-126.

WITHERS PC (1992) Comparative animal physiology. Saunders College Publishing, Forth Worth, Texas. $1,067 \mathrm{pp}$.

YATES FE (1979) Comparative physiology: compared to what? American Journal of Physiology 237: R1-R2. 